\title{
A case report of spontaneous rupture in unscarred
} uterus

\begin{abstract}
Background: Uterine rupture is a life-threatening obstetrical complication whose incidence has been increasing. Case: 27 years old patient, gravida two, para one, at $39 w 3 d$, referred from a District Hospital severely ill, Glasgow Coma Scale 10/15, BP: 70/42, Pulse: 134, Sat: $85 \%$ on room air and HB: $3,2 \mathrm{~g} / \mathrm{dl}$. Ultrasound showed Free fluid in abdominal cavity, uterine rupture, fetus out of the uterine cavity, no fetal heart activity seen. The patient was transferred to the theatre, delivered stillborn male baby, weighing $3221 \mathrm{gr}$. There is a fundal uterine rupture that was extended until both uterine cornoas. Total Abdominal Hysterectomy was undertaken by Richardson Technique and the patient was discharged seven days later. Conclusion: Spontaneous uterine rupture is rare in the unscarred uterus. However, can happen any time and in any trimester.
\end{abstract}

Keywords: abruptio, uterine rupture, unscarred uterus, hysterectomy, trimester
Volume 6 Issue 2 - 2020

\author{
Leandro Torriente Vizcaíno,' Danelys Cuellar \\ Herrera $^{2}$ \\ 'Obstetrics and Gynecology, Mofumahadi Manapo Mopeli \\ Regional Hospital, South Africa \\ ${ }^{2}$ Pediatrics, Mofumahadi Manapo Mopeli Regional Hospital, \\ South Africa
}
Correspondence: Leandro Torriente Vizcaíno, Obstetrics and Gynecologist, Mofumahadi Manapo Mopeli Regional Hospital, Phuthaditjhaba, Free State, South Africa, Tel 07I-526I738, Email leandro.torrient@yahoo.com

Received: February 13,2020 | Published: March 19, 2020
Abbreviations: IUFD, intrauterine fetal death; SFH, symphysis-fundal height; BP, blood pressure; ICU, intensive care unit; PNC, postnatal care; TOLAC: trial of labour after cesarean delivery

\section{Background}

Uterine rupture is a life-threatening obstetrical complication which incidence has been increasing. this condition usually occurs in the setting of the trial of labour after cesarean delivery, in patients with a history of trauma in the third trimester and few reports have described its occurrence in early pregnancy. this rare complication has an incidence of $<1 \%$ in women with scarred uteri, however, it is extremely rare in the unscarred uterus with a suggested incidence of only $0.006 \%$. $^{1,2}$

\section{Case presentation}

27 years old patient, gravida two, para one, no comorbidities. She had frequent visits at Primary Health Care, and had Normal booking blood; HIV and Syphilis were negative, and positive Rh. She was referred at 39 weeks from a District Hospital with a diagnosis of Placenta Abruptio and Intrauterine Fetal Death (IUFD). On admission, maternity record did not show any evidence of hypertension during pregnancy. According to the relatives, there is no history of trauma, or accidents etc.On physical examination patient was semi-conscious, severely ill, with Glasgow Coma Scale of 10/15, BP: 70/42, Pulse: 134, O2 Sat: $85 \%$ on room air and HB of $3,2 \mathrm{~g} / \mathrm{dl}$. Abdomen on palpation; $\mathrm{SFH}$ at $38 \mathrm{~cm}$, very tender and fetal parts easily palpable. ltrasound showed free fluid in the abdominal cavity, uterine rupture, fetus out of the uterine cavity, no fetal heart activity seen. With this diagnosis, the patient was transferred to theatre for an emergency cesarean section. The patient underwent general anaesthesia, Pfannenstiel incision performed, hemoperitoneum about 3 Liters of blood, delivered stillborn male baby, weight: 3221 gram. There is a fundal uterine rupture that was prolonged until both uterine horns (FIGURE 1 and 2); also active bleeding noted, so Total Abdominal Hysterectomy by Richardson Technique was performed. The patient was transferred to ICU for hemodynamic control and monitoring. Received blood, plasma and others medication for three days, after that was transfered to PNC and discharged four days later in stable condition with BP: 132/81, pulse $78, \mathrm{O} 2$ and Sat: $98 \%$, HB of $11.4 \mathrm{~g} / \mathrm{dl}$.

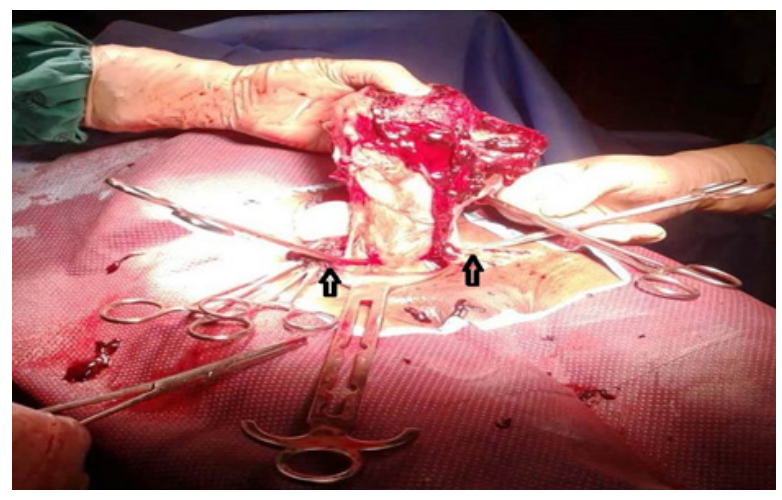

Figure I Arrows show uterine arteries clamped. Also uterus fundus completely open.

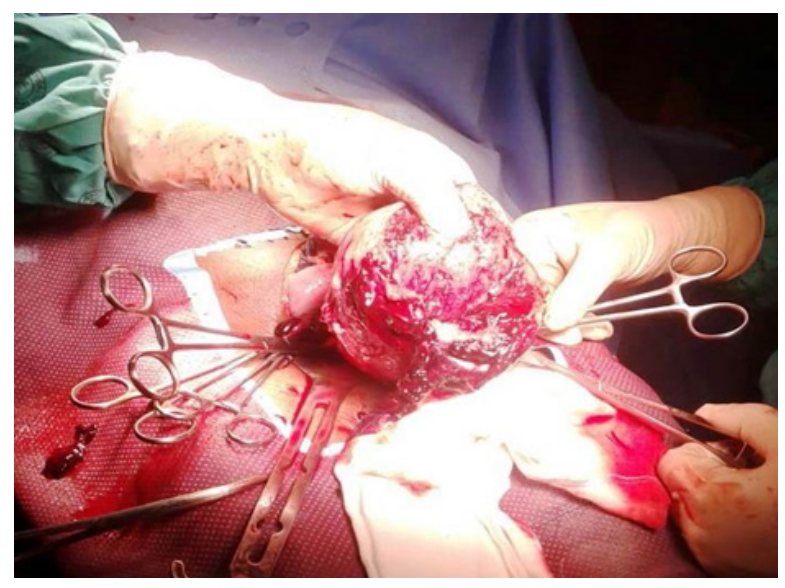

Figure 2 Uterus fundus completely open. 


\section{Discussion}

Uterine rupture consists of an obstetrical emergency that is becoming more frequent in developed countries, perhaps because of increasing cesarean section rates. ${ }^{3}$ Although the majority of cases occur in late gestation, mainly during TOLAC, very few reports have described its occurrence in the first and second trimesters of pregnancy, whether in scarred but also (rarely) in unscarred uteri. ${ }^{4,5}$ Spontaneous uterine rupture in the second trimester of pregnancy without prior uterine surgery or trauma is rare. Reported cases in the literature suggest underlying etiologies of abnormal placental implantation, congenital uterine abnormalities such as the bicornuate uterus and uterine septum. Occasionally, no underlying cause is found..$^{6-8}$

In this particular case, no risk factors were found, same results found Sun HD et al., ${ }^{9}$ in one case report published in 2012. There are many causes of abdominal pains who was the principal symptom reported by the patient. We can divide in obstetrics and none/ obstetrics causes, like gastritis, peptic ulcer, appendicitis or urinary tract infection. ${ }^{10}$ Antepartum hemorrhage is caused by different etiologies such as Placenta Previa, Placenta Abruptio, Uterine Rupture, and Vasa Previa with or without velamentous umbilical cord insertion. That is why sonar plays an important role in the early diagnosis and management ${ }^{11}$. Must be performed it is possible by experimented personnel because in the third trimester is more difficult found the myometrial defect. Also is recommended when the patient is stable.

The management of uterine rupture depends first of all of the clinical findings, localization, extension, parity, the expertise of the surgeon and mother condition. When the defect is small, the uterus can be either repaired or hysterectomy can be done, ${ }^{12}$ like in this case.

\section{Conclusion}

Spontaneous uterine rupture is rare in the unscarred uterus. However, it can happen any time and in any trimester, the quick diagnosis and management can save both the mother and fetal life.

\section{Acknowledgments}

None.

\section{Conflicts of interest}

The author declares that he has no conflicts of interest.

\section{Funding}

None.

\section{References}

1. Miller DA, Goodwin TM, Gherman RB, et al. Intrapartum rupture of the unscarred uterus. Obstet Gynecol. 1997;89((5 Pt 1)):671-673.

2. Hofmeyr GJ, Say L, Gulmezoglu AM. WHO systematic review of maternal mortality and morbidity: the prevalence of uterine rupture. BJOG. 2005;112((9)):1221-1228.

3. Miranda A, Castro L, Rocha MJ, et al. Uterine Rupture in Early Pregnancy. Int J Pregn \& Chi Birth. 2017;2(6):00046.

4. Tola EN. First Trimester Spontaneous Uterine Rupture in a Young Woman with Uterine Anomaly. Case Reports in Obstetrics and Gynecology. 2014:967386.

5. Ijaz S, Mahendru A, Sanderson D. Spontaneous uterine rupture during the 1st trimester: a rare but life-threatening emergency. Journal of Obstetrics and Gynaecology. 2011;31(8):772.

6. Peirzynski P, Laudanski P, Lemancewicz A, et al. Spontaneous rupture of unscarred uterus in the early second trimester: a case report of placenta percreta. Gineko Pol. 2012;83(8):626-629.

7. Agu PU, Okaro JM, Mbagwu UK, et al. Spontaneous rupture of gravid horn of bicornuate uterus at mid trimester--a case report. Niger J Med. 2012;21(1):106-107.

8. Damiani GR, Gaetani M, Landi S, et al. Uterine rupture in a nulliparous woman with septate uterus in the second trimester of pregnancy and review in literature. Int J Surg Case Rep. 2013;4(3):259-261.

9. Sun HD, Su WH, Chang WH, et al. Rupture of a pregnant unscarred uterus in an early secondary trimester: a case report and brief review. $J$ Obstet Gynaecol Res. 2012;38(2):442-445.

10. Ho WY, Wang C, Hong SC, et al. Spontaneous Uterine Rupture in the Second Trimester: a Case Report. Obstet Gynecol Int J. 2017;6(4):00211.

11. Vaknin Z, Maymon R, Mendlovic S, et al. Clinical, sonographic and epidemiologic features of second and early third-trimester spontaneous antepartum uterine rupture: a cohort study. Prenat Diagn. 2008;28(6):478-484.

12. Sreelatha S. A Rare Case of Uterine Rupture in an Unscarred Uterus. Gynaecology and Perinatología. 2018;2(3):281-284. 